\title{
Ruina/basural: Lógicas temporales y espaciales de la ciudad de La Paz en Saenz y Viscarra ${ }^{1}$
}

\author{
Irina Alexandra Feldman \\ Middlebury College
}

\begin{abstract}
This article analyzes spatio-temporal logics in the representation of the city of La Paz in Imágenes Paceñas by Jaime Saenz and the urban chronicles of Víctor Hugo Viscarra. Juxtaposing the concepts of chrononormativity and queer time, it explores how linear temporal logic remains insufficient for the understanding of the city and its inhabitants in the two narrative projects. The article postulates that the marginal spaces of architectural ruins and garbage dumps, and the marginalized people who inhabit queer space-time are key to "revealing the hidden city" and understanding its contradictory place in the national narrative and space.
\end{abstract}

\footnotetext{
${ }^{1}$ Este artículo se escribió en el marco de la convocatoria para un volumen en honor del Centenario del nacimiento de Jaime Saenz (octubre 1921), para una edición especial del Bolivian Studies Journal/Revista de Estudios Bolivianos. Quiero agradecer a Raquel Alfaro y Tara Daly por gestionar el proyecto y por su apoyo en el proceso de escritura. Sus sugerencias han sido claves para enriquecer el artículo y aclarar el argumento. De igual manera, agradezco las utilísimas conversaciones con Ixs colegas del Grupo de Escritura en Middlebury: Laura Lesta García, Patricia Saldarriaga, Fernando Rocha y Roberto Pareja. Este artículo se ha enriquecido en los intercambios y discusiones compartidas con estxs queridxs colegas.
} 


\section{Keywords}

Chronicle, Jaime Saenz, La Paz, ragpicker, ruin, queer-time, Víctor Hugo Viscarra, Walter Benjamin

\section{Resumen}

Este artículo analiza las lógicas espacio-temporales en la representación de la ciudad de La Paz en Imágenes Paceñas de Jaime Saenz y las crónicas urbanas de Víctor Hugo Viscarra. Empleando los conceptos juxtapuestos de la crononormatividad y el tiempo queer, explora cómo la lógica lineal temporal resulta insuficiente para la comprensión de la ciudad y sus habitantes en los dos proyectos narrativos. Se postula que los espacios marginales de ruinas arquitectónicas y basurales; y las personas marginadas que habitan el espacio-tiempo queer, son claves para "revelar la ciudad oculta" y entender su tensionado lugar en la narrativa y el espacio nacionales.

\section{Palabras clave}

Crónica, Jaime Saenz, La Paz, ruina, tiempo queer, trapero, Víctor Hugo Viscarra, Walter Benjamin

Dos grandes bebedores y narradores de la ciudad de La Paz, Jaime Saenz y Víctor Hugo Viscarra, comparten el mismo propósito declarado en sus crónicas: revelar la ciudad oculta. Comparten también la metodología de conocimiento empírico que consiste en prácticas de la vida cotidiana: narración literaria, consumo de alcohol en búsqueda de estados cercanos a la muerte, el caminar las calles de la ciudad. Sin embargo, lo que entienden por la "ciudad oculta" es muy diferente. Lo oculto de Saenz mora en los dominios metafísicos, mientras lo de Viscarra reside en el ámbito estrictamente material; lo que a la vez determina el corte subjetivo del periplo urbano de Saenz - a manera de Bildungsroman, un género literario explorado en su obra maestra Felipe Delgado-que se opone a la preocupación social de Viscarra. Las dos narrativas constituyen dos caras de la ciudad de La Paz: las crónicas de Saenz buscan lo andino eterno; las de Viscarra, lo perecedero y la podredumbre que acompaña la finitud. La estética de las descripciones obedece los parámetros de los dos proyectos. En Saenz, está la decrepitud hermosa, nostálgica, anclada en las ruinas y las calles de La Paz, donde las figuras humanas, descritas en una prosa impecable, igual que la que describe la arquitectura, quedan incorporadas como arquetipos en el gran escenario de la ciudad mítica. 
Aparte de la figura del aparapita, muy estudiada por la crítica saenceana, estudio aquí otra figura central para el proyecto de Saenz: el morador de los basurales, descrito como un enigma y como una cifra de acceso privilegiado al conocimiento. ${ }^{2}$ De modo dialéctico y complementario, las crónicas testimoniales de Víctor Hugo Viscarra describen para el lector el sufrimiento apenas aguantable, oculto a los ojos de la sociedad por su condición de marginado, del mismísimo habitante de basurales paceños, pero esta vez narrado desde su experiencia de sobrevivir en la helada noche altiplánica. La mirada de Saenz es exterior y su objetivo es el despliegue epistémico de la figura del marginado que no reconoce su destitución verdadera. En este sentido las crónicas de Viscarra constituyen un complemento necesario al trabajo de historiografía paceña de Saenz.

En la descripción de Saenz de La Garita de Lima se condensan varias temporalidades y los espacios que les corresponden dentro del proyecto de Imágenes paceñas. Esta descripción, asimismo, apunta hacia el mundo de experiencias vivenciales marginales en las que Viscarra, a su vez, ancla la experiencia citadina mostrando la naturaleza de la necesaria complementariedad de que hablo:

Ni siquiera la fea plataforma de cemento, que tan sólo data de
unos cinco o seis lustros atrás, ha sido suficiente desatino para
menoscabar el inexplicable, frío y austero encanto de la Garita de
Lima, la populosa al par que desolada plaza paceña, en la que
suelen reunirse los desocupados, los vagos y malhechores de los
barrios altos; en la que fenecen las calles Max Paredes y Tumusla,
y en la que esta última cambia de nombre y se convierte en la
avenida Baptista, que sigue su curso hasta el Cementerio General
para fenecer a su vez en las puertas de Villa Victoria. (27. Mi
énfasis)

Los personajes de Viscarra - desocupados, vagos, malhechores de los barrios altos - aparecen de manera furtiva en el esbozo de Saenz. Es a través de la lupa de las crónicas de Viscarra que se puede observar de cerca, enfocarse, en esta parte de la realidad paceña. Las vivencias de los marginados, las cuales, según estaremos viendo, habitan la "temporalidad queer" que

\footnotetext{
2 Notablemente, considerando la centralidad del alcohol como método de conocimiento para este autor, por lo menos en la primera etapa de su carrera literaria, entre los personajes de la ciudad de La Paz en Imágenes paceñas no está el personaje de "el borracho". Las crónicas de Víctor Hugo Viscarra complementan, con amplia exploración de este personaje, el retrato de la ciudad y sus habitantes.
} 
implica la práctica cotidiana temporal excéntrica y sobre todo que huye de la normativa de tiempo que obedece al mandato de la acumulación capitalista, corresponden también a sus espacios: "Ios barrios altos", en este caso. En este mismo párrafo, vemos las terribles tensiones temporales que marcan todo el proyecto de Imágenes paceñas. La voz del autor expresa claramente la angustia frente a los cambios en estructuras y edificios. La "fea plataforma" en el centro de la plaza que data de unos cinco o seis lustros es señal de estas transformaciones que angustian la nostálgica voz autorial. Como si fuera necesario contrapesar este malhadado cambio, el texto dedica una larga oración a establecer la exacta ubicación geográfica de la Garita de Lima, sugiriendo que la planificación urbana preserva siempre su núcleo histórico y garantiza la permanencia de la ciudad (algo que, además, podemos confirmar consultando los mapas de la ciudad de La Paz desde la Colonia hasta nuestros días). En la Garita de Lima "fenecen las calles Max Paredes y Tumusla, etc.". El mapa general de la ciudad que emerge de esta metonímica y minuciosa descripción de una de sus partes, está anclada en los sitios claves que protagonizarán las imágenes: la calle Max Paredes, el Cementerio, Villa Victoria. En lo que sigue, veamos cómo se definen con más precisión las diferentes temporalidades de la ciudad de La Paz y los espacios que les corresponden.

\section{Las temporalidades de la ciudad en Saenz y Viscarra:}

El tiempo metafísico. El tiempo histórico. El "tiempo queer" (Halberstam 1): Imágenes paceñas de Saenz entiende la ciudad de La Paz por medio del trabajo con temporalidades múltiples y muchas veces divergentes. El retrato de La Paz resulta literalmente multifacético, como en un prisma reflejado en los "lugares y personas de la ciudad" que habitan estas distintas temporalidades. El Illimani, la montaña, es la seña de la eternidad, de lo que no cambia; es el ancla que permite la vehemente declaración saenciana de que La Paz "No morirá" (11) nunca. La Plaza Murillo, el centro administrativo de la ciudad, una metonimia espacio-temporal del tiempo de la nación boliviana, se aferra a un punto en la flecha del tiempo lineal de la historia nacional y el espacio imaginado de la misma; se le suman Villa Victoria y la figura de la chola del mercado. El basural del Cerro Laikakota y sus habitantes, junto con la muy estudiada figura del aparapita, habitan lo que Halberstam llama "la temporalidad queer" (1) que se opone a las instituciones de la familia, la heterosexualidad y la reproducción que la sociedad patriarcal y capitalista impone a las personas. 
Halberstam postula que lo "queerness" de las prácticas espaciotemporales no normativas, excéntricas, no es circunscrito por las experiencias vitales de las personas sexual o genéricamente no binarias. "Queer time" es definido como "a term for those specific models of temporality that emerge within postmodernism once one leaves the temporal frames of bourgeois reproduction and family, longevity, risk/safety, and inheritance" (6) [un término para aquellos modelos específicos de temporalidad que emergen dentro del posmodernismo una vez que uno deja los marcos temporales de la reproducción y la familia burguesas, la longevidad, el riesgo / seguridad y la herencia] e incluye "the possibility that all kinds of people, especially in postmodernity, will and do opt to live outside of reproductive and familial time as well as on the edges of logics of capital accumulation" (10) [la posibilidad de que todo tipo de personas, especialmente en la posmodernidad, opten por vivir fuera del tiempo reproductivo y familiar, así como también al margen de las lógicas de acumulación de capital]. ${ }^{3}$

Como veremos a lo largo de este artículo, es en este sentido que estaremos considerando a los sujetos y las prácticas de la temporalidad queer. Los paceños de los cuales vamos a hablar pueden ser o no ser, implícita o explícitamente creativos en términos de las identidades de género o preferencias y prácticas sexuales. Pero los moradores del cerro Laikakota en Saenz y los protagonistas de las crónicas de Víctor Hugo Viscarra, todos habitan la temporalidad queer que desobedece a las lógicas de acumulación capitalista. En Saenz, las vivencias marginales que habitan esta tercera temporalidad, la temporalidad queer, se van acercando a la primera temporalidad de lo eterno y de conocimiento místico que va ligado con ello. Lo que las une - ¿qué puede unir la eterna montaña del Illimani y el habitante del basural? - es el afán de la huida del tiempo capitalista de producción material y reproducción social que está ligada con las prácticas espaciales también "excéntricas", atadas a ciertos sitios precisamente fuera del centro de la ciudad: el basural, la cantina, la calle y la montaña.

Se han observado los innegables lazos que unen a Jaime Saenz con los textos del otro, más reciente cronista de La Paz, Víctor Hugo Viscarra - ver por ejemplo "Víctor Hugo Viscarra, heredero no reconocido de Saenz", artículo publicado en el diario Opinión en 2019. Aquí precisaremos en qué consiste esta conexión. Ambos hacen uso del alcohol como práctica epistémica. La noche es el momento privilegiado de sus vivencias, y los antros (cantinas,

\footnotetext{
${ }^{3}$ Las traducciones de textos originalmente publicados en inglés pertenecen a la autora.
} 
bodegas) son los espacios centrales en sus narrativas. Ambos ponen en el centro figuras de marginalidad extrema, como los aparapitas y la gente sin techo. Los dos obsesivamente recorren la geografía de La Paz en sus crónicas. Se ha notado que la figura del aparapita paceño trabajada por Saenz en su poesía, en Felipe Delgado, y en Imágenes paceñas, adelanta el trabajo de Viscarra con la multiplicidad de personajes marginales de la ciudad. Para matizar, de entrada notemos que el proyecto de Viscarra es más concentrado que el de Saenz. Viéndolos a través del enfoque comparativo de las lógicas espacio-temporales, observamos que mientras el proyecto de Saenz navega las múltiples temporalidades e interpreta el espacio de la ciudad y sus personajes con las herramientas que cada una de estas temporalidades le ofrece, el de Viscarra habita y se centra en una dimensión temporal que resiste a las lógicas institucionales -las "strange temporalities, imaginative life schedules" (Halberstam 1) [extrañas temporalidades, cronogramas imaginativos de la vida] que cita Halberstam al definir la temporalidad queer. La exploración de estas temporalidades está determinada por el objetivo estético y epistémico de cada cronista: el conocimiento místico en Saenz; la búsqueda de la verdad social y la denuncia de la misma, en Viscarra.

Precisaremos más los términos teóricos referidos a lógicas temporales y espaciales alternativas con la ayuda del resumen ofrecido por Mariela Solana, quien revisita los conceptos críticos sobre temporalidades tanto en el trabajo de filósofos del tiempo como Johannes Fabian y Reinhart Koselleck, como en estudiosos que ligan la crítica del sentido común de entender el tiempo a la perspectiva de estudios queer, como Carolyn Dinshaw, Elizabeth Freeman y José Esteban Muñoz. La primera distinción útil para el presente trabajo es entre el tiempo metafísico y la temporalidad experimentada (Solana 43-44). Mientras el primero se refiere al tiempo homogéneo del universo, la segunda se refiere a la temporalidad como es habitada, sentida y utilizada por los seres humanos en la experiencia vivida. Aquí ciertamente vamos a estar más preocupados por la temporalidad experimentada, aunque también será obligatorio tocar, aunque sea tangencialmente, el tiempo místico de los dioses y la metafísica, a lo que nos obliga la naturaleza del pensamiento saenceano (que no Viscarra).

En segundo lugar, definiremos los términos que se refieren a lo que la sociedad capitalista adopta como el sentido común en cuanto al manejo temporal de la vida: el tiempo naturalizado y la crononormatividad. A partir del trabajo de Elizabeth Freeman, Solana vincula la crononormatividad a la temporalidad fomentada por el sistema capitalista, para organizar la vida de los cuerpos humanos hacia la máxima productividad (Solana 47, Freeman 3). 
Aunque no hay nada natural en este manejo de tiempo - tal como en el supuesto mandato de dormir 8 horas, trabajar 8 horas, y usar las 8 horas restantes para el dudosamente denominado "ocio" - esta lógica se acepta como la natural y necesaria. Paso siguiente, el aporte de los estudios queer muestra que estos sentidos comunes se basan en la imposición de la lógica heteronormativa, que impone a las vidas humanas una supuesta progresión obligatoria y privilegia ciertos usos del tiempo: el paso de la infancia a la adultez; la reproducción biológica y la social; la longevidad como la meta más deseada. Aunque autores como David Harvey, Michel Foucault o Pierre Bourdieu ya habían expuesto como se llegó a naturalizar cierta normativa temporal, Solana muestra que los estudios sobre la temporalidad queer consiguen "poner el acento en los ideales de género y sexualidad que están a la base de la naturalización del tiempo" (50).

De manera útil para mi análisis, el trabajo de Carolyn Dinshaw universaliza el término de la temporalidad queer al referirse a "formas de ser deseantes y corporeizadas que no están en sintonía con las mediciones habitualmente lineales de la vida cotidiana", y la teorización de Jack Halberstam define, como hemos visto arriba, el "queer time" como las prácticas que subvierten la lógica de acumulación capitalista, y que es practicado por "all kinds of people" que buscan la salida de esta lógica (Solana 56, Dinshaw 4, Halberstam 1). Tales son los moradores del basural en Saenz y los niños delincuentes y las trabajadoras sexuales que conoceremos en las crónicas de Viscarra.

Nuestros dos cronistas, Saenz y Viscarra, usan una voz autorial claramente masculina y con autoridad epistémica. El "yo" narrativo de Viscarra presume de sus conquistas, siempre heterosexuales. A la vez, dialécticamente, el testimonio viscarriano siempre reconoce, por así decir, la alianza de clase -si consideramos el Lumpenproletariat como clase- entre el personaje del narrador y los que Viscarra llama "mi gente": mujeres maltratadas, prostitutas, homosexuales, niños drogadictos. ${ }^{4}$ La voz autorial de Saenz habla, a ratos, en fórmulas casi axiomáticas, casi proféticas: "Ya el morador de las alturas lo sabe; no es la montaña que se mira. Es la presencia de la montaña" (Imágenes paceñas 17). A la vez, las personas marginadas ocupan un lugar central en su

\footnotetext{
${ }^{4}$ Cita de una de las pocas entrevistas de Viscarra concedida al periódico chileno La Nación, el 19 de junio de 2005. En ella, expresó lo siguiente: "Vivo en mi mundo. Estoy por mi gente, porque son mis delincuentes, son mis putas, mis maracos, mis mendigos, mis ladrones. El único portavoz que ellos tienen soy yo. Para mí la escritura es como una especie de desahogo. ¡Nunca esta maldita sociedad me ha dado algo!” (“Víctor Hugo Viscarra, heredero no reconocido de Saenz").
} 
narrativa, ofreciendo la clave para llegar al conocimiento de la realidad "oculta", esencial de la ciudad de La Paz. Ya hemos adelantado que lo esencial en Saenz es el conocimiento místico; mientras en Viscarra lo que se busca es la verdad social. Esta diferencia de propósito, como veremos en más detalle, determina el distinto acercamiento de estos escritores a las figuras de marginalidad.

Lo que une los dos proyectos, sin embargo, es el desvío del tiempo naturalizado dentro de la lógica crononormativa que los define. Los sujetos de sus crónicas son sujetos devenidos queer según la definición de Halberstam, a causa de la corporeizada desviación temporal. Complejizando aún más, Elizabeth Freeman muestra como el tiempo lineal de trabajo fabril y de la historia de la nación se normaliza a la par de la circularidad temporal de la esfera doméstica: el tiempo lineal marcado como dominio masculino y el tiempo circular como femenino (Solana 50, Freeman 5). Pero en las crónicas de Saenz y Viscarra no existe esfera doméstica; la erosión entre las esferas pública y privada garantizan la borradura de estos espacios. En Imágenes paceñas "los lugares y personas" de la ciudad pertenecen exclusivamente al espacio público - la calle, la plaza, el mercado. En Viscarra, todo sucede en las calles o en lugares públicos, incluso actos privados por excelencia, como tener sexo, defecar, morir. Por consiguiente, la doble articulación del tiempo normalizado es disuelta en estas crónicas, ya que no existe ni el tiempo lineal del trabajo, ni el tiempo circular de la esfera doméstica. ¿Qué los sustituye? Las prácticas repetidas de caminar la ciudad, emborracharse, conversar, estar sentado pensando y buscar, a manera del trapero (rag-picker, le chiffonnier) de Benjamin, los medios mínimos para mantenerse con vida.

Como ya dije, el interés de este trabajo está en los espacios y figuras que subvierten el tiempo naturalizado, que habitan el "queer time" y los espacios donde esta práctica temporal se despliega. Pero primero, para situar esta temporalidad y los lugares que le corresponden, visitaré brevemente las dos primeras temporalidades en Imágenes Paceñas de Saenz - que no en Viscarra, quien circula dentro de la temporalidad queer exclusivamente. Visitaremos, entonces, primero, el tiempo metafísico de conocimiento fuera del tiempo vivido por los humanos; y el tiempo progresivo, naturalizado, de la historia nacional, que goza de una presencia sorprendentemente imponente en Imágenes paceñas. 


\section{Temporalidad metafísica y la historia como catástrofe: el Illimani y las ruinas}

En La Paz, el Illimani, una de las montañas nevadas más altas, lo determina todo. Lo declara Saenz y lo puede confirmar cualquiera que ha estado en esta ciudad andina. Siendo la capital más alta del mundo, a 3,600 metros sobre el nivel del mar, La Paz marea por la pura falta de oxígeno. El Illimani domina La ciudad, elevándose por sobre ella con sus más de 6.000 metros de altura. En palabras de Saenz, "El Illimani se está —es algo que no se mira [...] Ya el morador de las alturas lo sabe; no es la montaña lo que se mira. / Es la presencia de la montaña" (Imágenes paceñas 17). ¿Cuál sería la diferencia entre la "montaña" y "la presencia de la montaña"? La formulación de Saenz apunta a la "presencia" del Illimani cuya aura y efecto en la ciudad y su gente no se limita al hecho físico o geológico de un pico nevado de exactamente 6.438 metros de altura. Esta presencia está fuera de los parámetros de medidas humanas - ha sido, es, y será anterior y posterior a la existencia de los seres humanos; y su presencia física en un momento dado condensa estas temporalidades, afectando la percepción de su cuerpo rocoso.

Notemos, en contraste, que en las crónicas de Víctor Hugo Viscarra, el Illimani no se menciona. Ni una vez. Los personajes de estas crónicas brutales están demasiado destruidos para mirar hacia la montaña (incluso si no se la mira, según Saenz). Siempre están mirando hacia el piso, para no caerse de hambre, de borrachera, por la golpiza recibida de la policía; o al vaso, con su líquido Salvador; o al culo con el cual están practicando la cópula del momento. No levantan la mirada. Así, en su lenguaje corporal, manifiestan que están condenados al tiempo de la vivencia humana, la temporalidad experimentada (Solana 40-41), sin la posibilidad de vínculo a otro espacio-tiempo metafísico, que vaya más allá de su finitud.

Saenz dedica Imágenes paceñas "A la ciudad de La Paz". En la Introducción, lamenta los cambios que ha sufrido la ciudad en las décadas que van entre los años 1920 y 1970. Observa estos cambios con ojo nostálgico y critica el observado empujón del "huracán llamado progreso" que arrasa con las calles coloniales de la vieja La Paz. Llora por la arquitectura perdida, por el derrumbe de los viejos tambos de adobe y por el hecho de que en su lugar se erijan horrorosos "hoteles" (41). La globalización -el poder del mercado que todo lo arrasa y todo uniformiza, creando un "espacio liso" (Deleuze y Guattari) para permitir la suave circulación del capital- aterra a Saenz. Frente a su innegable empuje y las huellas de la "destrucción creativa" capitalista (Harvey), Saenz declara la indestructibilidad de la ciudad de La Paz. La visión 
de la historia que se perfila en muchas de las crónicas de Imágenes paceñas es cercana a la idea de catástrofe benjamineana, en oposición a la idea del progreso triunfante. ¿Qué se transforma, entonces, y qué se preserva en este proceso? ¿Cuál es el núcleo "eterno" —según Saenz-, ese núcleo que precisamente es el objeto de su búsqueda?

En el más oscuro confín de algún barrio [...] allí puede encontrarse el espíritu de la ciudad, la cifra de muchos misterios - en un patio, en la superficie ruinosa de una pared, en los gastados peldaños que ya a nadie sirven; en el sitio en que ayer se hallaba una casa. Y lo que esto significa, en toda su hondura, podría explicarse por paradoja, pues muchas veces, como es bien sabido, la destrucción de una ciudad ha sido la verdadera causa de su definitiva permanencia (Imágenes paceñas 9. Itálicas en el original).

La enigmática prosa saenceana pone la poesía frente al empujón capitalista y defiende con ehemencia a La Paz como una ciudad irrepetible, evocando, digamos, a los espíritus del lugar, explícitamente a las montañas que presiden la ciudad, según la tradición espiritual aymara que ha inspirado las investigaciones místicas del escritor, ya que: "En efecto, nadie puede negar que La Paz es una ciudad andina; y como tal subsistirá. Así nos lo asegura el espíritu rector que habita la montaña. Esta ciudad no se verá desvirtuada; no dejará de ser lo que es. No morirá" (11, Itálicas en el original). La Paz es perpetua por el hecho de ser una ciudad andina - por su localización geográfica, por ser parte del paisaje de la cadena montañosa, por el compromiso con los saberes aymaras del escritor. Esta perpetuidad contrasta con la evolución y cambio que caracteriza a la nación boliviana, a no ser por cierta calidad estática presente en la metonimia de la Plaza Murillo o el personaje de la chola del mercado, como veremos más adelante.

Las ruinas sirven en esta narrativa como puente entre la eternidad que ocupa la "presencia de la montaña" y el discurso historicista. Las ruinas, en Imágenes paceñas, aparecen en oposición a los lugares centrales y plenamente reconstruidos, claves para la historia oficial de la ciudad, tales como el Mercado Rodríguez o la Plaza Murillo, pero a la vez sirven un propósito complementario en la historiografía de La Paz. El discurso saenceano continúa una fuerte tradición de historiografía europea donde las ruinas garantizan la permanencia y la continuidad histórica; son la señal y cifra del pasado y de la historia. Al analizar el caso de la historiografía australiana, Carlo Salzani resume el mecanismo por el cual los colonizadores europeos pudieron negarles la historia precolonial a los aborígenes del continente: "no encontraron 'ni castillos, ni ruinas', y concluyeron que los indígenas australianos 'no tenían 
historia' o estaban 'fuera de ella'” (224). Así, la presencia de las ruinas garantiza precisamente la profundidad histórica del lugar. A la vez, condensa varias temporalidades que resisten el empuje renovador de la temporalidad del progreso capitalista: las ruinas están en el presente, pero representan para el ojo del observador el tiempo pasado. Según Benjamin, "In the ruin history has physically merged into the setting. And in this guise history does not assume the form of the process of an eternal life so much as that of irresistible decay" (Benjamin, The Origin of German Tragic Drama, cited in Stephens 156) [En la ruina, la historia se ha fusionado físicamente con el escenario. $Y$ de esta manera la historia no asume tanto la forma del proceso de una vida eterna como la de una decadencia irresistible]. En las ruinas del patio abandonado Saenz se sale de la visión oficial del progreso histórico y se adhiere a la visión de la historia como un proceso de declive y podredumbre. A la vez, establece un polo dialéctico frente a la eternidad de la montaña - la temporalidad metafísica, fuera del tiempo de la experiencia humana, que se opone a la lógica capitalista. Su vehemente declaración de que La Paz "no morirá" se apoya en esta tensión de la montaña que no cambia y los restos (ruinas) del artificio humano que siempre permanecen frente a la lógica de sustitución capitalista que requiere que lo nuevo reemplace, sin resto, a lo viejo, el proceso que implica la creación perpetua de mercado de consumo. Como veremos en lo que sigue, en Imágenes paceñas los espacios "oficiales" de la ciudad - a diferencia de la eternidad de la montaña y la evidencia de una catástrofe que son las ruinasse insertan en la historicidad de La Paz, siempre balanceándose entre la lógica de permanencia y la lógica de renovación y, de esta manera, insertándose en la lógica temporal del desarrollo capitalista.

\section{Espacios de historicidad: Plaza Murillo, Villa Victoria y Mercado Rodríguez}

El tiempo historicista se despliega en Imágenes paceñas en tres localidades distintas entre sí y, sin embargo, todas claves para la articulación de la narrativa lineal, progresista y conforme al proyecto de construcción nacional. El primer lugar es la Plaza Murillo, el centro citadino y la sede de gobierno; el segundo es Villa Victoria, un barrio pobre, tradicional, de obreros; y el tercero es el más antiguo mercado paceño, el Mercado Rodríguez. La conjunción de los tres lugares es clave para articular la geografía nacional en la capital en esta narrativa que establece la equivalencia de intereses entre, por un lado, las élites gobernantes y su poder institucional, tal como se plasma en la sede del gobierno; y las masas populares urbanas que habitan y circulan 
por los espacios de los barrios populares y el Mercado - en contraste con la realidad histórica de masas populares indígenas que decididamente se oponen a tales intereses, como fue el caso de las comunidades indígenas del lago Titikaka durante la Guerra del Chaco.

“La Plaza Murillo", un apartado de Imágenes paceñas, no deja de sorprender tanto como parte del corpus (poético y narrativo) saenceano, así como en relación al autor, borracho y místico. A institucionalismo, historicismo, hasta a burocracia suena esta reseña:

La plaza Murillo resume la historia de Bolivia en su totalidad [...] Cada centímetro de sus aceras y de sus calles, cada ventana y cada puerta de los edificios que la circundan, cada árbol y cada poste en sus cuatro costados conocen la sangre que los paceños han vertido, siempre con nobleza y en todo instante, en defensa de la libertad y de la justicia. Indudablemente la propia configuración de la plaza Murillo, así como la ornamentación pública y los edificios, han sufrido cambios a lo largo de los años, mas hay algo que no ha variado ni podrá variar jamás, y es el espíritu rector por el que este sitio de la Patria, ubicado en La Paz precisamente, constituye hoy y siempre el más alto símbolo de la bolivianidad. (Imágenes paceñas 67)

El centro geográfico y simbólico del poder en la ciudad de La Paz funciona en esta instancia del discurso saenceano a través de la conjugación de dos temporalidades: la historicista y la místico-eterna. La sangre de los paceños se vierte "siempre" y el espíritu patriótico "no ha variado ni podrá variar jamás". La permanencia y la repetición es también clave en la descripción del barrio popular donde habitan estos mismos paceños que "siempre" han vertido su sangre en la plaza Murillo.

"Villa Victoria", desde la perspectiva de Saenz, es:

Barrio de obreros, de gente que lucha y gente que sufre; en todo alzamiento popular, en toda refriega, en todo combate, a lo largo de la historia sangrienta que ha dado a La Paz la fama que tiene, Villa Victoria ha estado siempre a la vanguardia [...] es por tradición un baluarte de bolivianismo; este sector de la ciudad, templado en sacrificio, forjado en el dolor y la muerte, ya en tiempos de la Guerra del Chaco ha dado pruebas del más elevado amor a la Patria". (33)

La expresión "a lo largo de la historia" y la palabra clave "siempre" señalan este afán de la continuidad que Saenz busca en la ciudad y sus personajes 
frente a los cambios que trae el fin del siglo XX. El énfasis en la Guerra del Chaco, otra vez, subraya a los obreros ideales de Villa Victoria en su función de soldados listos para derramar su sangre por la patria, que separa a este sector popular de las comunidades indígenas que siempre han presentado una robusta oposición al reclutamiento.

"El Mercado Rodríguez", es una crónica en la que la chola paceña emerge como figura de la identidad nacional:

El Mercado Rodríguez, como institución precisamente, es inseparable de la chola paceña, la cual es por derecho propio su dueña y señora. Pues si la chola paceña ha ocupado siempre un lugar de privilegio en el espíritu nacional, ello se debe a sus extraordinarios méritos y virtudes, habiendo bregado esforzadamente ya desde la colonia y en la Guerra de la Independencia, y habiendo aportado consecuentemente invalorables al par que decisivas contribuciones a la fundación y formación de nuestra cultura y nuestra Sociedad. (57)

El mercado aquí está visto como una "institución", en una ligazón explícita con la sede del gobierno antes mencionada. En un franco acto de apropiación de un sujeto indígena urbano, la chola paceña, Saenz privilegia momentos cuando las mujeres indígenas urbanas fueron instrumentales para avanzar el trabajo de construcción nacional, por ejemplo, en la guerra de la independencia. Sin embargo, es importante que no se borre de nuestras consideraciones la historia profunda, cuando el ingreso de personas con atuendo indígena al centro de la ciudad de La Paz fue prohibida; o los instantes, entre ellos los más recientes, cuando mujeres de clases populares en La Paz - muchas de ellas precisamente cholas del mercado- fueron centrales en las insurrecciones contra las políticas neoliberales del gobierno de turno y objeto de sus represiones, tal como ocurrió en la guerra del gas en el año 2003.

De manera contrastante y complementaria, en la crónica "Las cafeteras del Mercado Rodríguez", de Víctor Hugo Viscarra, vemos la vida nocturna del mismo mercado, que nos revela una realidad difícilmente apropiable por el discurso historicista o patriótico, y que testimonia la invasión de otra lógica temporal en este espacio urbano:

En una de las aceras del mercado Rodríguez, cada noche arman sus toldos una decena de mujeres que venden café con sandwich tanto a los negreros (choferes que trabajan toda la noche y que en su mayoría ni siquiera tienen brevet) como a los noctámbulos que 
aman la noche tanto como a las mujeres. Las más conocidas son: la negra Antonia, la Ely, la Pascuala, La Nora, la Edith y la Naty (Natividad, para los que no la conocen). (Borracho estaba, pero me acuerdo 124)

Con esta última aclaración sobre el nombre de Naty/Natividad, Viscarra marca de entrada un lazo social con las mujeres que describe: la voz narradora claramente sí conoce a Naty. Procede a describir como estas mujeres trabajan toda la noche, atendiendo a sus clientes en su puesto de café y dentro de las movilidades. Lejos de ser un símbolo de espíritu nacional, las mujeres del Mercado Rodríguez en Viscarra son destinos privados, individuales, disgregados. Entre ellas no sólo encontramos a "la chola paceña", sino a mujeres que practican, performativizan y negocian varias identidades étnicas. Por ejemplo, la negra Antonia, "había temporadas en que ella se cambiaba la ropa y de la noche a la mañana aparecía vestida de cholita [...] una buena temporada se perdió del Mercado [...] Pero a los pocos meses regresó, otra vez vestida como señora y siguió atendiendo a sus clientes" (124-125). Aquí la afroboliviana paceña Antonia se viste de cholita mientras tiene un compromiso estable por unos meses con un chofer, quien le prohíbe que venda café; pero cuando reaparece en su lugar de trabajo, de nuevo "se viste de señora", es decir, usa la ropa del mainstream global (jeans) y sigue ejerciendo el oficio no tan oculto de la trabajadora sexual. Saenz describe la actividad del mercado Rodríguez de día - mientras el mercado, por más popular que sea, es "prácticamente una institución" y funciona dentro de la temporalidad del discurso historicista, donde la figura de la chola paceña puede ser articulada con el resto de la comunidad nacional. Al contrario, Viscarra describe la actividad que se despliega en este mismo mercado de noche. ${ }^{5}$ En Viscarra la noche $-\mathrm{y}$ específicamente la noche helada altiplánica - es un personaje aparte que ataca con una saña especial a los marginados y los borrachos.

La noche, notemos, es la seña de la salida de la temporalidad crononormativa, un "queer time" por excelencia. Los borrachos y los marginales de Viscarra habitan la noche, y - como complemento lógico- no trabajan de día, como dictaminan las reglas del uso del tiempo dentro de la sociedad capitalista. La noche es el segmento temporal al cual corresponden con especial afinidad -en ambos Saenz y Viscarra - los espacios marginales

\footnotetext{
${ }^{5}$ Aunque en su poesía y en su novela Felipe Delgado, Jaime Saenz privilegia la noche como espacio de búsqueda epistémica, en las crónicas de Imágenes paceñas es más bien la cara diurna y oficial de la ciudad lo que se representa.
} 
de la ciudad. En este punto es donde los dos narradores se encuentran, y allí vamos nosotros en lo que sigue.

\section{Las "desviaciones temporales": los basurales y sus habitantes}

Recordemos que Jaime Saenz dedica su obra "A la ciudad de La Paz". En contraste, Viscarra, en general, no escribe dedicatorias, pero una de las crónicas más extensas en la colección Ch'aqui fulero (2007) lleva la siguiente dedicación: "Un homenaje a mis amigos del Patronato de Menores, allá por los años 74-75" (103). La crónica describe la vida de los niños en esta institución, con todo el abandono y abusos que padecen. Otra vez apartándose de lo grande, Viscarra se enfoca en lo más, literalmente, pequeño: los niños huérfanos y delincuentes, casi todos ellos ya muertos en el momento en que escribe esta crónica, a mediados de los años 80 . ¿Qué temporalidad puede habitar una persona en el Patronato de Menores, con 6 años de edad, inmerso en una rutina diaria carente de cualquier actividad productiva o formativa; cuya mayor meta es robar de la cocina un pedazo extra de pan y huir del abuso de los compañeros? Ciertamente no puede ser reglamentada por las expectativas y normas que rigen la lógica temporal que valora la longevidad como meta deseada, o que estructura la vida de los individuos con el propósito de obtener la máxima productividad. La vida de esta persona transcurre fuera de la división entre espacio público y esfera doméstica, y por lo tanto carece de la subdivisión temporalidad lineal y temporalidad circular propia del orden capitalista (Freeman 5-6). La temporalidad que habita este niño está a la vez sujeta a ciertas normas (se le deja ver la tele los domingos pero no otros días) y fuera de ellas (está todo el día apoyado contra la pared, pensando cómo escapar, sujeto a los azarosos pedidos del director a lavar el piso del patio).

La vida en el Patronato de Menores, igual que la vida en la cárcel o en un manicomio, programa a las personas a quienes supuestamente tiene que "corregir", a vivir dentro de una práctica continua de la "desviación temporal" o "temporalidad extraña" (Halberstam 1). Podemos resumir tales "desviaciones" en, como mínimo, tres categorías amplias: 1) rechazo de longevidad como meta; 2 ) rechazo de la división día/noche atada a horarios de trabajo determinados por una lógica capitalista; 3) rechazo de la prescrita progresión de etapas de la vida guiada hacia la reproducción biológica y social. La vida en el basural lleva esta "desviación" a su último límite. 
Como en las crónicas de Viscarra, Imágenes Paceñas también explora las desviaciones temporales como parte indispensable del retrato verdadero de la ciudad de La Paz, en varias composiciones dedicadas a personajes marginales. El basural urbano constituye allí una especie de punto de contraste al discurso historicista descrito en el apartado anterior. La centralidad estructural de los basurales para obtener una comprensión de la ciudad y sus habitantes es evidente en la organización misma de Imágenes paceñas. En las crónicas de Viscarra es en los basurales, espacios todavía más marginales que los barrios populares y geográfica y simbólicamente distantes de las calles y plazas del centro de la ciudad, donde transcurre la mayor parte de acción. Ambos, Saenz y Viscarra, encuentran el entendimiento de la realidad de la experiencia humana en estos sitios de máxima abyección, donde los seres humanos conviven y luchan por la comida con los animales.

Imágenes paceñas está subdividido en dos secciones. La primera se titula "Lugares" y describe parajes de La Paz, mientras la segunda se titula "Personas" y habla de los "tipos" paceños. La sección "Lugares" concluye con una crónica titulada "En el cerro de Laikakota". ${ }^{6}$ De esta manera, esta crónica sirve como una especie de puente entre "Lugares" y "Personas", porque aunque pertenece al apartado de "Lugares", a diferencia de otras crónicas de este apartado, habla de los moradores de este lugar en lugar de concentrarse en la descripción de edificios y construcciones. La línea entre lugar y ser humano (habitante) se desdibuja. Ya desde el título es diferente de otras crónicas, que describen un lugar y, aunque también comentan lo que ocurre en este lugar, se centran en el lugar como en un ente estático en sí: "La calle Linares", "El patio", etc. La última crónica, al contrario, cuenta lo que sucede en el cerro Laikakota. Y lo que está allí es un "basural impresionante y de proporciones en verdad gigantescas, ofreciendo un cuadro macabro y de pesadilla, con espesos mantos de humo que se ciernen sobre un vasto sector y que se desprenden de hogueras dantescas, las que devoran incesantemente las ingentes y siempre renovadas acumulaciones de basura" (127).

\footnotetext{
${ }^{6}$ El destino del cerro Laikakota presenta un ejemplo estelar de los cambios del espacio urbano que Saenz desea documentar y que le sirven como material de reflexiones teóricas. El "basural titánico" queda, para el 2021, convertido en un Parque Mirador urbano con placitas infantiles. Este hecho crea un sugerente contrapunteo a la idea saenceana que ve toda transformación del espacio urbano como pérdida y degradación.
} 
Saenz procede a describir a los habitantes del basural. ¿Está Saenz exteriorizando su propia búsqueda mística al proyectar sus divagaciones hacia personas indigentes? Puede ser. Hay que observar la exterioridad de la descripción, pero a la vez sorprende la insistencia en remarcar la dignidad y legitimidad de la opción de vida que encarnan las personas que Saenz encuentra en el basural:

Y este basural titánico es de por sí un verdadero paraíso para muchedumbres de seres que moran en profundas concavidades del cerro y que, si no son precisamente demonios, como que en rigor no lo son, han de constituir en todo caso una humanidad extraña en grado sumo, formada como está toda ella por criaturas que parecerían haber salido del averno para burlarse y para mofarse de un mundo que desprecian por no corresponder seguramente a su modo de vida, fundado a partir de una visión de las cosas que difiere radicalmente de aquella que rige la conducta de los demás, pues para ellos, la civilización y las buenas costumbres, el trabajo y los valores y las normas, y todo lo demás, no son sino mera patraña [...] Pues estas criaturas, que parecen haberse confabulado para hacer escarnio de los dictados de la sociedad, y que parecen haber renunciado voluntariamente a la existencia para vivir una muerte, vale decir para morir una vida verdadera, podría afirmarse que no son nada, pero sin embargo, al mismo tiempo son todo. Son ellos. No son ni pordioseros, ni malhechores, ni asesinos, pero son ellos. [...] Alguna vez uno se topa con uno que otro de estos seres [...] Y uno se queda estupefacto con su trato cordial y sincero, con su dignidad y buenas maneras y con su lenguaje, objetivo y concreto, con su humildad y lucidez, con su admirable y profundo sentido de humor, todo lo cual, según resulta evidente, sólo corresponde a hombres libres y totalmente dueños de sus actos, en consonancia con cierta armonía interior. $(127,129)$

Las denominaciones que usa Saenz para referirse a las personas que habitan el basural son variadas, usando vocabulario que a toda costa evita las palabras "gente" o "persona". Son "no precisamente demonios", son "criaturas", son "seres", "una humanidad extraña en grado sumo"; "podría afirmarse que no son nada, pero sin embargo, al mismo tiempo son todo"; $y$, finalmente, con cierto triunfo, su comportamiento "sólo corresponde a hombres libres y totalmente dueños de sus actos". Este vocabulario establece, por una parte, la diferencia radical entre los habitantes del basural y "un mundo que desprecian". Por otra parte, encuentra en la vida en el basural la búsqueda del conocimiento a través de los estados cercanos a la muerte - tales como la borrachera, viendo el valor de la vivencia de los moradores del cerro Laikakota en "haber renunciado voluntariamente la existencia para vivir una muerte, vale decir para morir una vida verdadera". Claramente, para 
Saenz, la vivencia en el basural es una especie de askesis elegida que lleva a una sabiduría; es una práctica epistémica que puede ser comparada con la práctica sostenida de los estados liminales como la de la borrachera.

La tensión entre la askesis de la vida cotidiana en el basural y el hedonismo de la borrachera se mantiene, aunque las dos prácticas llevan al umbral de la muerte. Dentro de las prácticas epistémicas de Saenz, el estar al borde de la muerte es un requisito para llegar a un conocimiento, y es por eso que la descripción de las personas del cerro Laikakota está escrita en clave de admiración. Vale la pena recalcar que la descripción de estos "seres" es ofrecida por una voz narrativa externa a sus condiciones de vida; y que es una voz, sin embargo, que expresa admiración y valora esta vivencia liminal. La diferencia radical, al parecer, no los sustrae de la "humanidad" en su más digno sentido. Un término de esta descripción, sin embargo, resulta problemático: "voluntariamente". ¿Habrán renunciado estas personas, o por lo menos algunas de ellas, a la vida en la urbe por su propia voluntad, o han terminado en esta condición por la lógica de desecho, aplicada a las personas y las cosas, propia de la modernidad capitalista? Mi respuesta, con la ayuda de Viscarra es: no, no están allí por su propia voluntad. Las personas no terminan en la calle por su propia voluntad, esto es romanticismo. Las prácticas de askesis y la borrachera, en cuanto prácticas liminales, son una necesidad; y pueden ofrecer, o no, un acceso "privilegiado" al conocimiento.

Tal romantización de la figura de marginalidad absoluta que despliega Saenz en Imágenes paceñas y en sus otros textos, a pesar de nuestro caveat, es teórica e historiográficamente productiva, tal como lo evidencia el trabajo de Walter Benjamin sobre la figura del trapero (Lumpensammler, ragpicker, chiffonnier). A través de esta figura, Benjamin desarrolla "a philosophy of historical leftover" (Le Roy 127) [una filosofía del resto histórico] o una "theory of trash" (Salzani 190-214) [teoría de la basura]. Es desde esta figura de miseria más extrema, igual que a través de los hechos y figuras históricos que quedan excluidos del archivo de la narración historicista, que la verdad de la historia y de la modernidad se revela. Para Benjamin, la figura del trapero cifra la rebelión de la práctica del método materialista para escribir una historia contra el historiador que escribe sobre eventos grandiosos, narrativas maestras y grandes hombres. Hay un paralelo entre la clasificación de los desechos practicada por el trapero y el trabajo de un archivista: los dos clasifican la realidad según un criterio profesional. Pero también son las caras opuestas de la misma moneda: mientras el archivista organiza los archivos de la historia oficial, el trapero recoge los pedazos de realidad que fueron excluidos del archivo. En este sentido, Benjamin (igual que Saenz y Viscarra) trabaja con 
estos trozos de la realidad desechada, y de hecho dice que "deja que los trozos interactúen y hablen por sí mismos", dejando que la materialidad actúe libremente al margen de la intencionalidad del historiador. Sin embargo, según demuestra Carlo Salzani en su minucioso estudio de la figura del chiffonnier en Benjamin:

As in the case of the prostitute, the figure of the ragpicker is "romanticized." Baudelaire and Benjamin are interested in ragpickers as an allegory of urban modernity, but fail to acknowledge their real destitution. On the one hand, Benjamin is victim to the fascination with the "exotic" marginal, which characterized certain elite avant-garde intellectuals, to the myth of the "privileged position" of the dispossessed "within the domain of knowledge" [...] Ragpickers fascinate Benjamin as allegories, but their humanity is overlooked. (Salzani 193-194)

[Como en el caso de la prostituta, la figura del trapero está "romantizada". Baudelaire y Benjamin están interesados en los traperos como una alegoría de la modernidad urbana, pero no reconocen su verdadera miseria. Por un lado, Benjamin es víctima de la fascinación por lo "exótico" marginal que caracterizaba a ciertas élites intelectuales de vanguardia, por el mito de la "posición privilegiada" de los desposeídos "dentro del dominio del conocimiento" [...] Los traperos fascinan a Benjamin como alegorías, pero su humanidad es pasada por alto]

Pero, aún con estas limitaciones, "the Lumpensammler as allegory provides both a perfect methodology for redemptive practice and a constructive strategy for 'conspiring' against the capitalist order" (Salzani 194) [El lumpen como alegoría proporciona tanto una metodología perfecta para la práctica redentora como una estrategia constructiva para "conspirar" contra el orden capitalista]. Específicamente, la práctica vivencial -aquello que Bourdieu denomina habitus - del trapero, igual que la de los moradores de basurales o los niños del orfanato, subvierte la lógica temporal del tiempo capitalista de producción y consumo, igual que la demanda de renovación constante que acompaña esta lógica. El trapero, sujeto que usa el tiempo para recorrer la ciudad en búsqueda de los desechos con el propósito de clasificarlos y reciclarlos, trabaja dentro de lo que hemos denominado temporalidad queer, igual que el habitante del basural en Saenz y Viscarra, y se niega a desechar lo usado siguiendo la lógica de la renovación continua, ya que vive de lo que la máquina de producción capitalista desecha. Regresando a la figura de la ruina por un momento, diríamos que tanto la figura simbólica del marginado como la ruina sirven para desviar la narrativa histórica lineal, siempre señalando la 
presencia de restos que resisten a la sustitución "limpia" y el olvido que acarrea.

En Imágenes paceñas, entonces, presenciamos un uso alegórico de la figura del residente de los basurales, que apunta al acceso privilegiado al "dominio del conocimiento" gracias a la extrema marginalidad que lo empuja a estados cercanos a la muerte. La mirada de Saenz, como la de Benjamin, es exterior y su objetivo es el despliegue epistémico de la figura del marginado, pero no reconoce su destitución verdadera. En este sentido las crónicas de Viscarra constituyen un complemento necesario al trabajo de historiografía paceña de Saenz: arrojan luz a lo que queda oculto en las descripciones saenceanas, exteriores y distanciadas, de las personas que viven en precariedad, dentro de las prácticas temporales excéntricas y en los espacios que les corresponden, tales como los basurales urbanos.

Viscarra también dedica varios textos a las descripciones de la vida en los basurales, y hay dos que sobresalen en la colección Borracho estaba pero me acuerdo: "Basurales" y "Amigos perros". Viscarra se aproxima a los basurales desde la narración de un testigo ocular, con tono cercano al de un reporte, práctico, desapasionado, informativo. Empieza con una lista, sin rodeos, de los principales basurales de La Paz, entre los cuales - observemosno figura el cerro Laikakota. Paso seguido, Viscarra declara la necesidad de análisis de los basurales $y$, de inmediato, para entender cómo funciona este espacio, lo ata a una temporalidad alternativa: "Aunque parezca innecesario, creo que hay que hacer una especie de análisis de los basurales, porque siendo los depositarios de lo que desechan aquellos que usan la noche para descansar, son fuente de sustento para quienes esperan la noche para buscar, tanto su alimento como la materia prima para sus fuentes de trabajo" (38). Prosigue a describir personas que recolectan botellas de vidrio para venderlas a las fábricas de vidrio; otras que recolectan huesos que "son vendidos a las fábricas de alimentos balanceados"; aquellas que recogen latas y otros trozos de metal para ser reutilizados en "la Universidad de San Pedro" (la cárcel principal de la ciudad de La Paz); las mujeres que buscan desechos para dar de comer a los chanchos; y otros "muchos" que buscan algo que les pueda servir de alimento - los desechos que "deben pelear con los perros para que éstos no se los quiten" (39). La crónica termina con una irónica y desgarradora frase: "Y este número de gente en los basurales se incrementa con los mocosos que llegan a alegrar con su presencia el ambiente" (39), que hace recuerdo al lector del ineludible destino de los niños en el Patronato de Menores. 
La crónica "Amigos perros" completa este cuadro con reseñas de biografías de las personas caninas que comparten las andanzas de los borrachos que viven en las calles, se alimentan, y queman cartones para calentarse en los basurales (226). Esta crónica, que cierra la colección Borracho estaba pero me acuerdo, expande la noción de subjetividad dignificada que Viscarra trabajosamente elabora a lo largo de sus crónicas y que abarca una diversidad de personas marginadas, desde los borrachos, delincuentes, trabajadorxs sexuales y personas no-binarias en términos de género o identidad sexual, a los "amigos caninos", cuyas condiciones de existencia se asemejan en puntos clave a estas otras figuras marginales.

Los basurales y sus personajes, en Saenz y Viscarra, son espacios que funcionan y son usados fuera de la lógica normativa. Estas figuras son claves para entender la realidad social, "no son nada, y sin embargo son todo" -esta realidad social que Saenz evoca en los sitios nodales del tiempo historicistaporque viven de los desechos de lo que la sociedad bota y ellas mismas son definidas como "desechos". Para Saenz, la existencia de los personajes del cerro Laikakota es admirable desde lejos, misteriosa en su organización -la voz narrativa declara no saber qué hacen todo el día, "qué hacen con su tiempo", aunque testimonia que, al hablar con ellos, manifiestan sabiduría y dignidad, lo que magnifica su misterio. Viscarra, asimismo, asevera e insiste en la dignidad de esta opción de vida; pero además revela el misterio, la razón de esa dignidad. Mientras Saenz se pregunta cómo y de qué subsiste el habitante del basural, Viscarra reporta cómo estas personas se aseguran la subsistencia con el trabajo de lo que llamaríamos hoy reciclaje y la reutilización de los recursos y materias primas. Aquí no hay misterio; estas prácticas de rescate y reutilización son lo único que, dentro de la existencia marcada siempre por el estado liminal de cercanía de la muerte, preserva estas vivencias, marcadas por la consciencia de su propia finitud.

Las prácticas temporales excéntricas son clave para entender la ciudad de La Paz en las obras de Saenz y Viscarra, pero el tipo de excentricidad es distinta en ambos proyectos. Se articulan tanto con la búsqueda transcendental saenceana como con la inmanencia y finitud humana de la obra de Viscarra. La ruina de un edificio en Saenz resiste a la lógica de acumulación capitalista al presentar el innegable resto (remainder) frente al requisito de la sustitución "limpia" que permitiera el flujo ininterrumpido del capital. En este sentido, se declara obstinadamente que la ciudad de La Paz "no morirá", pues se conservará "el alma de la ciudad" en los aspectos urbanos que resisten los cambios impuestos por la especulación inmobiliaria: la grilla de la ciudad (como vimos en la introducción con la descripción precisa de la ubicación de la Garita 
de Lima), las ruinas de los viejos tambos y casas, en fin, todos los personajes y lugares capturados en las páginas de Imágenes paceñas.

La ruindad humana testimoniada minuciosamente en las crónicas de Viscarra queda, al parecer, fuera de cualquier narrativa histórica, ya que señala la finitud del cuerpo sin otorgarle la posibilidad de que transcienda. Para los sujetos que habitan los espacios paceños marcados por la temporalidad queer no hay salvación religiosa, ni subsunción a la nación, ni herencia a través de la reproducción biológica. Las subjetividades marcadas por un inevitable fin habitan la urbe en un presente radical, sin pasado ni futuro. Viscarra complementa el retrato saenceano de la "oculta" ciudad de La Paz (léase, una que existe fuera de los usos normativos de espacio-tiempo) con relatos que revelan la verdad material de lo que queda como "misterio" en Saenz: la existencia liminal de los que habitan La Paz bajo la seña de precariedad humana, en un presente extremo.

\section{Bibliografía citada}

ANTEZANA, LUIS H. 2006. "Zavaleta leyendo Felipe Delgado". René Zavaleta Mercado, ensayos, testimonios, y re-visiones. Maya Aguiluz Ibargüen y Norma de los Ríos Méndez, coords. FLACSO-México, UNAM, CIDESUMSA. 163-170.

DELEUZE, Gilles and Félix Guattari. 1987. A Thousand Plateaus: Capitalism and Schizophrenia. Brian Massumi, trad. Minneapolis-London: University of Minnesota Press.

DINSHAW, Carolyn. 2012. How Soon Is Now? Medieval Texts, Amateur Readers, and the Queerness of Time. Durham, NC.: Duke University Press.

FREEMAN, Elizabeth. 2010. Time Binds: Queer Temporalities, Queer Histories. Durham, NC.: Duke University Press.

HALBERSTAM, Judith. 2005. In a Queer Time and Place: Transgender Bodies, Subcultural Lives. New York: New York University Press.

HARVEY, David. 2016. "Production of Capitalist Spaces". Lecture video.

Deterritorial Investigations.

[https://deterritorialinvestigations.wordpress.com/2016/04/03/davidharvey-production-of-capitalist-spaces/] página descargada el 7 de septiembre, 2021.

LE ROY, Frederik. 2017. "Ragpickers and Leftover Performances".

Performance Research 22 (8): 127-34.

[https://www.tandfonline.com/doi/full/10.1080/13528165.2017.1433

391] página descargada el 7 de septiembre, 2021.

MUÑOZ, José Esteban. 2009. Cruising Utopia: The Then and There of Queer Futurity. New York: New York University Press. 


\section{PARQUE MIRADOR LAIKAKOTA.}

[http://www.emaverde.com.bo/index.php/es/espaciosrecreacionales/parques-cerrados/laicakota] página descargada el 7 de septiembre, 2021.

SAENZ, Jaime. 2007 [1979]. Felipe Delgado. La Paz: Plural Editores.

---. $\quad$ 1979. Imágenes paceñas: Lugares y personas de la ciudad. La Paz: Difusión.

SALZANI, Carlo. 2009. Constellations of Reading: Walter Benjamin in Figures of Actuality. New York: Peter Lang.

SOLANA, Mariela. 2017. "Asincronía y crononormatividad. Apuntes sobre la idea de temporalidad queer". El Banquete de los Dioses. Revista de Filosofía y Teoría Política contemporáneas 5 (7): 37-65.

[https://publicaciones.sociales.uba.ar/index.php/ebdld/article/view/2 431] página descargada el 7 de septiembre, 2021.

STEPHENS, Bradley. 2007. "Reading Walter Benjamin's Concept of Ruin in Victor Hugo's Notre-Dame de Paris”. French Studies 61 (2): 155-66.

"Víctor Hugo Viscarra, heredero no reconocido de Saenz". 2019. Opinión Bolivia. [https://www.opinion.com.bo/articulo/ramona/v-iacute-ctorhugo-viscarra-heredero-reconocidoSáenz/20190120225000679142.html] página descargada el 7 de septiembre, 2021.

VISCARRA, Víctor Hugo. 2002. Borracho estaba, pero me acuerdo: Memorias del Víctor Hugo. La Paz: Correveidile.

---. 2007. Ch'aqui fulero: Los cuadernos perdidos de Víctor Hugo. La Paz: Correveidile, 2007.

New articles in this journal are licensed under a Creative Commons Attribution 4.0 United States License.

This journal is published by the University Library System of the University of Pittsburgh as part of its D-Scribe Digital Publishing $\underline{\text { Program, and is cosponsored by the University of Pittsburgh Press. }}$ 